\title{
Shared International Partnership Experience between Taibah University, KSA and George Washington University, USA: A SWOT Analysis and Strategic Plan
}

\author{
Fatemah Abdullah Alhazmi*
}

"My first objective is for our Country to be a pioneering and successful global model of excellence on all fronts; and I will work with you to achieve that..."

Custodian of the Two Holy Mosques: King Salman Bin Abdul-Aziz AlSaud (2016)

Shared International Partnership Experience between Taibah University, KSA and George Washington University, USA: A SWOT Analysis and Strategic Plan

Saudi Arabia, like many other countries worldwide, is striving to develop the necessary expertise and resources to address its future needs in all sectors. The Saudi government recognizes that all success stories begin with a clear vision, based on strong pillars. This is the objective of the plan entitled: 'Saudi Arabia's Vision for 2030' (2016) (henceforth in this research: Vision 2030), which was designed to progressively reduce Saudi Arabia's dependence on oil, through measures that support the development of a diverse economy, alongside key service sectors, such as health, education, infrastructure, recreation, and tourism. The current research does not aim to explain how Vision 2030 applies across multiple sectors; rather it highlights issues associated with the intention to build an education system aligned with the needs of the market, to create a strong economic foundation, based on a specific case.

The planned developments in education outlined in Vision 2030 can be achieved in a variety of ways at different levels. The plan seeks to address both general and higher education, through the preparation

*Department of Educational Administration,College of Education, Taibah University, Almadinah Almunawarah,Saudi Arabia 
Pجلة كلية التربية بالإسماعيلية - العدد الثامن والثلاثون - مايو Y Y P

of a modern curriculum, focused on achieving rigorous standards in literacy and numeracy, and character development by offering training and developing programs to educate teachers, by improving the learning environment to stimulate creativity and innovation, by improving current curricula and teaching methods, and, by refining students' values and core skills. The aim of these measures is to ensure graduates can fulfil the requirements for national development and meet the demands of the labor market. In part this will also involve increasing the level of private sector participation in the education sector.

Universities are currently playing an instrumental role in moving the country toward a realization of this vision. On the 25 th of April 2016, many details relating to Vision 2030 were announced by the Deputy Crown Prince Mohammad bin Salman Al Saud (Rashad, 2016). These included the initiation of 80 projects. One of these projects targets the objective of having at least five Saudi universities ranked among the top 200 universities in the international rankings. This requires educators to help students attain results above the international average, as determined by global education indicators. Participating in this important project, many of Saudi Arabia's universities are already working hard in a variety of different ways to improve their outcomes, so as to be instrumental in realizing Vision 2030. Saudi universities are expected to improve their academic programs for approval by the accreditation agency. The Ministry of Education has officially closed down academic programs requiring further development, subject to approval before implementation. Some of these programs are being developed autonomously by the relevant departments themselves, while others are being developed through international partnerships; a practice encouraged in Vision 2030.

While international university partnerships are not new (Jie, 2010), their numbers worldwide have greatly expanded in the last twenty years. Today, many Saudi Arabian universities are involved in international partnerships. This brings benefits to a wide variety of programs in different fields, providing access to new knowledge from different cultures and educational systems. According to the General Department of Planning and Statistics at the Ministry of Education (GDPSME, 2010), it has supported a number of contracts and partnership agreements to boost international research links across the Kingdom. For example, in 2010, King Saud University made nearly 54 
agreements with universities and research centers in France, America, Britain, India, China, Germany, Sweden, and Singapore. In addition, King Fahd University's Petroleum and Minerals' department has arranged cooperative relationships and strategic partnerships with global institutions, and local centers. In addition 10 active agreements have been approved by the National Center for e-learning and distance education with institutions with world class experience. In 2008, the number of participants involved in faculty research projects overseen by international teams had reached 369, including some university professors.

Moreover, the Ministry of Education has supported the establishment of International Advisory Councils at some universities, believing that attracting outstanding global expertise will deliver benefits in terms of the development of the university. For example, King Fahad and King Abdulaziz Universities' International Advisory Boards have organized a number of consultative Council meetings. Taibah University (TaibahU) is among those universities supported by the Ministry of Education to contract and arrange partnership agreements in various fields. The university' vision emphasizes the development of inputs and outputs: "Taibah University, is a comprehensive university dedicated to excellence in teaching, research, and community services" (Taibah University, 2017a).

TaibahU believes that pursuing partnership agreements is essential to achieving its mission, especially the development of high quality academic postgraduate programs. To this end, TaibahU has an Agency for Graduate Studies and Research, the primary purpose of which is to strengthen cognitive, cultural and scientific cooperation between members of the TaibahU community and their counterparts at local and international scientific institutions. In forging local cooperation and international cooperation the Agency aims to build bridges with administrations and authorities throughout the Kingdom and globally (Taibah University, 2017b).

The Parties to the International Partnership

Samoff and Carrol (2004) define a partnership as "a collaboration that can reasonably be expected to have mutual (though not necessarily identical) benefits that will contribute to the development of institutional and individual capacities at both institutions that respects the sovereignty and autonomy of both institutions..." (p.115). Herein, the researcher assumes that the current 


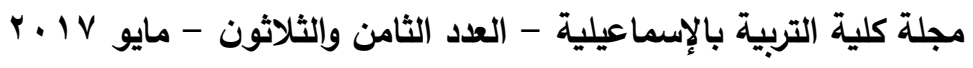

partnership offers an equal and harmonious academic collaboration, informing curriculum design (Ph.D. program), teaching, and research skills development.

Taibah University (TaibahU)

TaibahU was established in Medina, Saudi Arabia in 2003. Royal Decree number 22042 was issued stating the Council of Higher Education's decision to integrate the campuses of Muhammad bin Saud University and King Abdulaziz University into a single independent university in Medina; the resultant TaibahU includes 28 colleges (Taibah University, 2017).

TaibahU has witnessed a huge increase in the number of students (both men and women) enrolled over the last decade. In 2003, there were 7,761 students enrolled; in 2017, there are 20,815 students enrolled. The university currently delivers 156 academic programs, of which 94 are graduate programs. The seven levels of qualification awarded at TaibahU are Diploma, Associate, Bachelor's, General Diploma, Higher Diploma, Master's, and Doctorate. (Taibah University, 2017b).

The university's mission is:

- To provide high-quality academic programs in multiple areas;

- To develop and support research, including contributing to the enrichment of knowledge and the achievement of development goals;

- To meet the needs of national development and the requirements of the labor market to produce graduates capable of competing in the knowledge economy, in view of globalization;

- To strengthen the role of the TaibahU in terms of community services and building a knowledge society; and

- To provide a campus environment to support productivity and excellence. (Taibah University, 2017b).

The Department of Educational Administration

The Department of Educational Administration (DEA) is a major department within the College of Education at TaibahU. It mainly provides graduate level programs to prepare specialists in educational administration, leadership, planning and the economics of education. In addition, the department collaborates with the Ministry of Education, delivering training courses for school principals (school leaders) for two semesters each year. It also offers courses at Bachelor's 
level, contributing to the number of college graduates. The department is recognized as unique, and there is high demand for the programs it offers. High levels of cooperation among faculty members are intended to achieve excellence, and enrich knowledge and practice in the fields of leadership, administration, planning, policy, and economics, in education (Taibah University, 2017c).

\section{George Washington University (GWU)}

GWU is a congressionally chartered, not-for-profit corporation located in the District of Columbia, USA. The participants in the program described in this research are drawn from the University's Graduate School of Education and Human Development within the College of Education, as envisioned by the first President and created by an Act of Congress in 1821; GW is now the largest higher education institution in the nation's capital. Annually, GW enrolls a diverse population of undergraduates, graduates, and professional students from 50 states, the District of Columbia, and more than 20 countries, offering degrees (MA, EdS, PhD, and EdD) and Graduate Certificate programs to prepare future leaders who will apply the knowledge and analytical skills gained to shape education within society. Graduates of the program typically adopt administrative, academic and research positions in public, private, and charter schools and districts, at postsecondary institutions, associations, government agencies, counselling agencies, and, educational positions in business and industry. It offers comprehensive programs for undergraduates and graduates in the liberal arts, as well as degrees in medicine, public health, law, engineering, education, business, and international affairs (George Washington University, 2017).

The Graduate School of Education and Human Development (GSEHD)

The stated aim of the GSEHD is to develop a strong conceptual understanding of the relationship between theory, research, and practice; to develop scholars and scholarly practitioners able to analyze critical issues in the field, to deliver individualized attention to further students' progress, and to offer support for the successful completion of original student research. The GWU's GSEHD delivers a nationally recognized Education Administration program accredited by NCATE (a Specialized Professional Association). The current research describes the international partnership model linking TaibahU (Saudi Arabia) and GWU (United States of America). The author can confidently claim 


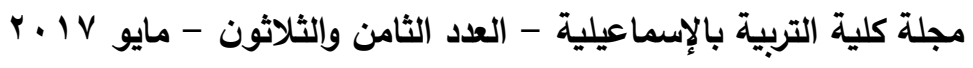

that no similar partnership exists at either TaibahU, or in any other College of Education at a Saudi Arabian university.

Research Questions

The present study was designed to answer the following questions:

- What is the strategic plan that forms the basis of the partnership between TaibahU and GWU, developed based on Sallis' model.

- What are the strengths, weaknesses, opportunities, and threats that emerged in the planning stages concluding with the pre-implementation stage?

Research objective

The present research clarifies the strategic plan developed informing the basis of the partnership between TaibahU and GWU, and identifies the strengths, weaknesses, opportunities, and threats that emerged in the planning stages, concluding with the pre-implementation stage.

Strategic planning process

Strategic planning enables a college to establish its priorities; and subsequently to decide how best to achieve them. As a participatory process, strategic planning builds trust and increases the confidence of staff, underlining the ability of the management team to handle change. It enables necessary organizational changes to be tackled in a rational manner, according to predetermined objectives. However, perhaps most importantly in the current context, it can be used to identify future opportunities. The strategic plan also provides direction, so that colleges can maximize their potential and minimize threats. In the case of the current partnership, strategic planning steps were followed in accordance with those set out by Sallis (1990) which matching with the current study. 
Shared International Partnership Experience--- Fatemah Abdullah

\section{Figure 1. Sallis' model of strategic planning}

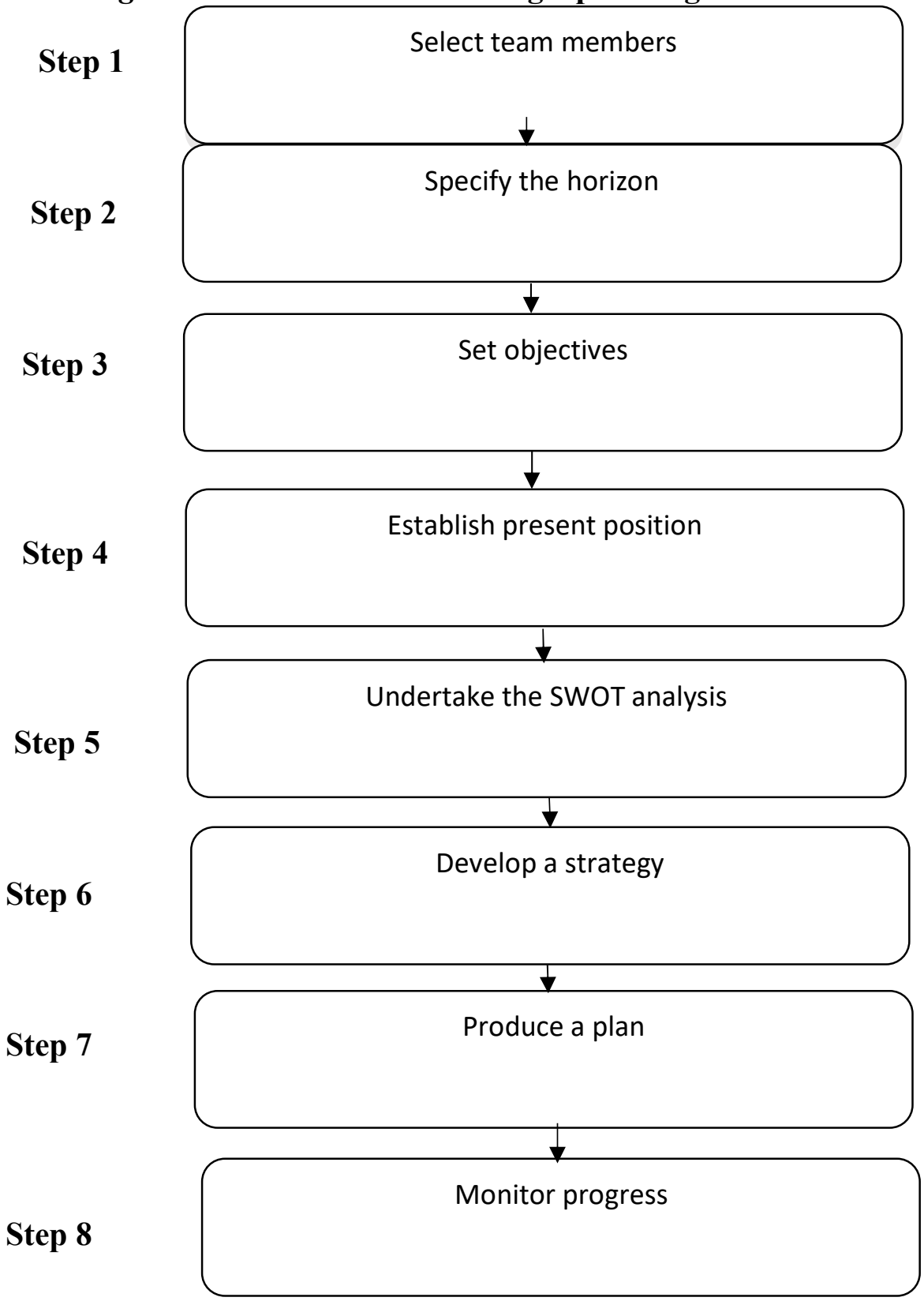

Source: Sallis (1990) 


$$
\text { مجلة كلية التربية بالإسماعيلية - العدد الثامن والثلاثون - مايو P. V م }
$$

Stage 1: Selecting the Planning Team

Collaboration on planning for this project involved the Department of Educational Administration (DEA), the College of Education, TaibahU, Saudi Arabia, and the Graduate School of Education and Human Development (GSEHD) at GWU, United States of America. The program was designed by a joint working group comprising faculty members from the Graduate School of Education and the Human Development Team (Graduate School of Education and Human Development, GSEHD) at GWU, and faculty members at the DEA. In the service contract setting out the development of a partnership agreement, three members from each university (TaibahU and GWU) were assigned as representatives to work together.

\section{Stage 2: Specify the Horizon}

The program was initiated by core faculty members at a breakfast meeting during the thirty-ninth annual conference of the International Society for Educational Planning (ISEP), held in October 2009 at Savannah, Georgia, United States of America. Some key members of the university leadership team were present at this meeting. The negotiation phase continued at subsequent conferences and webconferences until 2011. In 2012, members from GWU visited TaibahU and held a workshop, after which the scope and nature of the partnership were outlined. After sufficient preparation time had elapsed, GWU submitted a Memorandum of Understanding (MOU) for review. This triggered a lengthy discussion phase that continued until 2013. In 2014, the Department Chair, Dr. N., and a faculty member from the department, Dr. B., met separately with officials from TaibahU, to update them about the progress of the partnership, and at the end of 2014, the MOU was reclassified as a service contract. Finally, the service contract was signed by representatives from both universities. Signing took place on April 17 2015, at the International Exhibition \& Conference on Higher Education in Riyadh (IECHE). Stage 3: Set Objectives

The objectives set out presented the aim of the international partnership model; i.e., to promote academic cooperation through collaboration in curriculum design (Ph.D. program), teaching, and the development of research skills. The information concerning the design of the Ph.D. program specified that the first stage would be implemented by GWU based on a built-education system (Blended 
Learning), and that students would be awarded a certificate after completing their Master's degrees (Post Master Certificate, PMC). After which, TaibahU would implement the remaining component of the course: supervising the doctoral thesis. During the thesis preparation stage, GWU would be expected to play a consultative role and provide quality references.

Stage 4: Establish Present Position

In order to accomplish these objectives, both teams agreed on the following points and steps, to minimize the gap between the two universities' expectations, and to establish a foundation for the actions they would undertake:

- Appoint design teams;

- Develop a white paper;

- Launch a "Needs Assessment Questionnaire";

- Identify TaibahU's implementation capacity;

- Explore TaibahU's academic policies, accreditation requirements, and dominant pedagogical approaches;

- Identify areas of integration for the blended model;

- Align courses with TaibahU's strategic plan and national priorities;

- Assess and identify technology compatibility with the blended model;

- Identify a potential student profile; and

- Explore the potential for further collaboration in research, teaching, and student and faculty exchange.

First Workshop

After establishing the present position, the first workshop was held on December 5th to 11th, 2015, in Madinah Almunawwarah in Saudi Arabia. The TaibahU team had worked for three months to organize the workshop. It was scheduled to run over five working days; each day had a set target to encourage discussion among a specific audience of postgraduate students, faculty members, TaibahU leaders, and Deans of the colleges of education from different Saudi universities. Questionnaires were designed, distributed and analyzed during the workshop, and the data collected provided useful information about the program. (More details about the questionnaire and other methods used in this workshop and all phases of the partnership are available in the research methodology section.)

In addition, during the workshop, two presentations were given by two members from GWU, delivering information about the school's 
مجلة كلية التربية بالإسماعيلية - العدد الثامن والثلاثون - مايو PV

facilities and the PhD program. The main aims of this workshop were to establish a framework for the PhD in Educational Administration and Leadership and the Post Master's Certificate programs; to outline the program design and curriculum assessment; to establish a timeline; to review contents and standards; to obtain students', faculty members', and leaders' experiences and input; and to identify TaibahU's existing expertise and capacity for collaboration in the course design and implementation. The researcher was involved in the workshop as a member of the partnership, ensuring it was run successfully and that the members of both teams were able to collect sufficient information to assist in the development phases of the program. The workshop session concluded with a visit to Saudi schools and a university college in Yanbu industrial city, to give the GWU team a greater understanding of life in Saudi schools, so that they could develop a realistic and valid program.

Actions

After the first workshop the two teams prepared a reflective report, which also established a timeline for the next phase of the service contract. They developed a plan for PMC course delivery, and agreed on the final courses for inclusion in the new Ph.D. program in Educational Administration and Leadership. The team then prepared preliminary proposals for admission to the program, comparing the criteria for the Saudi National Accreditation with the academic standards set out at GWU. After this work, the framework for the doctoral program was discussed amongst the two teams in preparation for its translation. Finally, a second workshop was arranged at GWU, and a report on the second workshop added to the partnership file. This workshop is explained in greater detail in the following section.

Second Workshop

The second workshop was held at GWU from 24 October to 3 November $r+1 \%$. The aim of this workshop was to meet with GWU officials and course developers and review the syllabi before presentation to the institutional review board. It also included opportunities to provide information about Saudi Arabia and its education system, TaibahU, the College of Education, the DEA, and to summarize the aims of the partnership. The TaibahU team also trained on APA and Blackboard to prepare for the blended classes, and attended audit classes to learn how courses are delivered at GWU. The team also visited places in GWU and other public spaces. At the 
university they visited GWU facilities including libraries, student support services, technology, and the Center for Educational Policy. Outside the university they visited public schools to meet school leaders, teachers, and students in action at GWU, and in surrounding areas, including Capitol Hill, museums, and historical sites.

Final Stage before Implementation

After the second workshop the GWU-TaibahU design team met for reflection, feedback, and to establish guidelines for the final report to establish the forthcoming partnership duties. Additionally, the TaibahU team submitted a detailed report on the second workshop to the Ministry of Education, concluding with recommendations for the Ministry, relating to educational issues in general, and higher education in Saudi Arabia in particular. The TaibahU team members then presented a lecture to some TaibahU leaders (the Vice President of the university, the deanships of postgraduate studies, admissions and registration, and the college of education), summarizing the program's achievements and expressing the necessity to immediately action items to garner their support to gather circumstantial evidence. The presentation included requesting sufficient provision to access the developed materials for translation into Arabic, approving the Ph.D. program developed by the TaibahU council within a short time frame, allowing the admittance of doctoral students, identifying specific dates for preparing and beginning Ph.D. classes, and facilitating a Blackboard facility, either with GWU or supported by TaibahU.

Two months after the presentation, the program and course specifications were completed by team members at both universities, and provided in Arabic and English.

In addition to the program development steps described above, multiple additional processes were implemented to secure the success of the partnership; however, there is insufficient space to include all these details in a single article. The researcher also engaged in further research into the possibilities of the partnership, to evaluate and mentor the program's implementation, developing a course specification, and comparing the criteria for the National Accreditation with the academic standards applied at GWU.

Stage 5: Undertake a SWOT Analysis

Additional details, and a critical analysis of the program's development, are provided below in the form of a SWOT analysis, to better understand the program's strengths, and weaknesses, and the opportunities and threats encountered. It is important to acknowledge 
مجلة كلية التربية بالإسماعيلية - العدد الثامن والثلاثون - مايو PV

here that a SWOT analysis can be influenced by the agenda of the individual performing it. To mitigate this, an outside consultant, known to be an expert in international partnership concerns, reviewed the SWOT analysis. In addition, as a faculty member from the department, the reviewer was well-placed to observe the details of the partnership.

Since the 1960s SWOT analyses have been implemented to assist with strategic planning in various industries (Kotler, Armstrong, Harris, \& Piercy, 2013). Still widely used, the approach been improved to make it more useful as a tool for strategic management. A SWOT analysis examines not only where the organization is today, but also where it might be positioned in the future, as a basis for decision making. Despite the fact that there are different methods of analysis available the researcher chose a SWOT analysis in this case, as she has considerable experience using this method. In this research, the SWOT analysis refers to the partnership program specifically, not to the two organizations involved.

Research Methods

In order to conduct a SWOT analysis to understand the current partnership, as recommended in previous studies, the researcher selected multiple methods to attain an enhanced understanding of how humans construct their lives (Cohen, Manion, \& Morrison, 2007; Kadushin, Hecht, Sasson, \& Saxe, 2008; Patton, 2002). Consequently, in the current research, five methods were used to identify the situation prior to the program's implementation, and to establish the aims of future research designed to evaluate and monitor the partnership: questionnaires, interviews, content analysis, observation, and document analysis.

The questionnaires included two main sections: the first gathering personal information; and the second, based around seven items relating to the program: program content coverage, program uniqueness, program relevance, program pedagogy and approaches, partnership model, and contemporary topics to be covered during the workshop. In addition, semi-structured interviews were used, as they are more flexible than other methods (Smith, Harre, \& Vanlangenhove, 1999). The interviews were carried out, during the first workshop and over the four year planning period, with 35 faculty members and students from TaibahU and some faculty members at GWU. Nonparticipant observations, and content analysis supported the partnership journey, to reveal a comprehensive picture of the 
partnership. All the data was analyzed by the TaibahU team and utilized in the SWOT analysis.

The section below describes how the SWOT analysis was applied to frame the partnership between the two universities in terms of strengths, weaknesses, opportunities and threats. The SWOT analysis is intended to guide the involved parties to capitalize on their strengths, overcome weaknesses, exploit opportunities, and counter threats, and secondarily to create a strategic plan. The key areas are summarized and explained in the table and paragraphs below. The analysis reveals that some key strengths derive from weaknesses and that both the threats and weaknesses have positive features that inform the progress of the partnership, as will be explained at the end of this research. 


\begin{tabular}{|c|c|c|c|c|c|}
\hline \multicolumn{3}{|c|}{ Internal factors } & \multicolumn{3}{|c|}{ External factors } \\
\hline & Strengths & Weaknesses & Opportunities & & Threats \\
\hline $\begin{array}{l}1 . \\
2 . \\
3 . \\
3 . \\
5 . \\
5 . \\
5 . \\
5 .\end{array}$ & $\begin{array}{l}\text { GWU } \\
\text { enthusiasm, } \\
\text { great } \\
\text { cooperation, } \\
\text { flexibility of } \\
\text { partnership } \\
\text { with TaibahU. } \\
\text { Success of the } \\
\text { workshops held } \\
\text { at the two } \\
\text { universities } \\
\text { and the } \\
\text { achievement of } \\
\text { goals. } \\
\text { Students' } \\
\text { enthusiasm } \\
\text { about studying } \\
\text { in a program } \\
\text { based on a } \\
\text { partnership } \\
\text { project. } \\
\text { Program } \\
\text { suitable for } \\
\text { female students } \\
\text { who cannot } \\
\text { access study } \\
\text { abroad for } \\
\text { cultural or } \\
\text { family reasons. } \\
\text { Strong Support } \\
\text { from TaibahU } \\
\text { leaders. } \\
\text { New Vision } \\
\text { 2030 supports } \\
\text { partnerships in } \\
\text { education and } \\
\text { other fields. } \\
\text { Included in the } \\
\text { university's } \\
\text { vision and } \\
\text { mission. } \\
\text { Part of the } \\
\text { institution's } \\
\text { core values. } \\
\text { New Ph.D. } \\
\text { program in } \\
\text { Educational } \\
\text { Leadership and } \\
\text { Administration } \\
\text { based on } \\
\text { academic } \\
\text { standards } \\
\text { followed by the } \\
\text { GSEHD } \\
\text { (GWU) PMC }\end{array}$ & $\begin{array}{l}\text { 1. Bureaucracy. } \\
\text { 2. Resistance to } \\
\text { change. } \\
\text { 3. Too few } \\
\text { qualified } \\
\text { members of } \\
\text { staff available } \\
\text { to teach } \\
\text { courses. } \\
\text { 4. Student's } \\
\text { weaknesses in } \\
\text { English. }\end{array}$ & 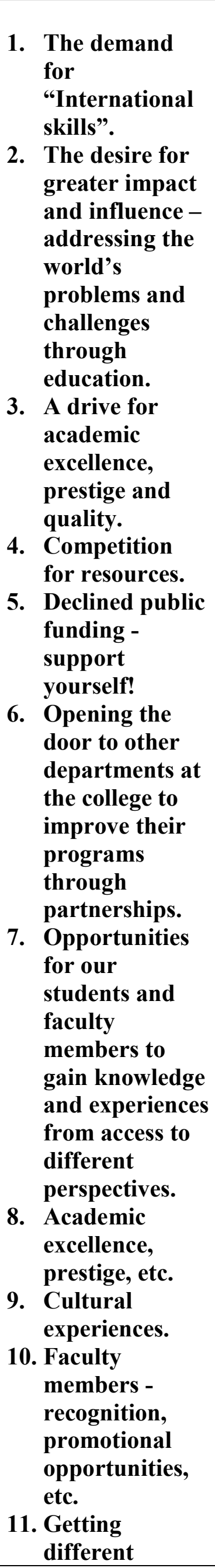 & 6. & $\begin{array}{l}\text { Time accuracy } \\
\text { and cultural } \\
\text { differences. } \\
\text { Program } \\
\text { approved. } \\
\text { Technological } \\
\text { threats. } \\
\text { Facilitates } \\
\text { access to } \\
\text { resources, } \\
\text { technology, } \\
\text { data and } \\
\text { expertise } \\
\text { required for } \\
\text { the research } \\
\text { project. } \\
\text { Discounting } \\
\text { differences in } \\
\text { academic } \\
\text { standards and } \\
\text { requirements } \\
\text { (Comp exam; } \\
\text { TOFEL; GRE, } \\
\text { credit transfer, } \\
\text { etc.) } \\
\text { Variations in } \\
\text { instructional } \\
\text { strategies, } \\
\text { student } \\
\text { expectations, } \\
\text { and faculty- } \\
\text { student } \\
\text { interactions in } \\
\text { different } \\
\text { cultural } \\
\text { traditions and } \\
\text { language. } \\
\text { Difficulty } \\
\text { sustaining } \\
\text { interest at the } \\
\text { highest level of } \\
\text { the institution } \\
\text { for program- } \\
\text { based faculty } \\
\text { initiated } \\
\text { partnerships. } \\
\text { Unexpected } \\
\text { and continuous } \\
\text { leadership } \\
\text { change. } \\
\text { Legal issues: } \\
\text { Intellectual } \\
\text { property, laws } \\
\text { and regulations } \\
\text { governing the } \\
\text { countries and } \\
\end{array}$ \\
\hline
\end{tabular}




\begin{tabular}{|c|c|c|}
\hline $\begin{array}{l}\text { from GWU } \\
\text { with a credit } \\
\text { transfer option } \\
\text { to the TaibahU } \\
\text { Ph.D. program } \\
\text { Teaching and } \\
\text { cultural } \\
\text { experiences } \\
\text { Consultations } \\
\text { and } \\
\text { monitoring. } \\
\text { 10. Joint student } \\
\text { projects. } \\
\text { 11. ISEP as a } \\
\text { revitalizing } \\
\text { force-help } \\
\text { roll forward } \\
\text { ideas, even } \\
\text { when } \\
\text { momentum is } \\
\text { slow and the } \\
\text { direction } \\
\text { unclear. } \\
\text { 12. Teaching and } \\
\text { cultural } \\
\text { experiences. } \\
\text { 13. A drive for } \\
\text { academic } \\
\text { excellence, } \\
\text { prestige and } \\
\text { quality. } \\
\text { 14. Consultations } \\
\text { and } \\
\text { monitoring. } \\
\text { 15. Research } \\
\text { collaborations } \\
\text { and joint } \\
\text { international } \\
\text { conferences } \\
\text { (ISEP). } \\
\text { 16. Team members } \\
\text { at the two } \\
\text { universities } \\
\text { have } \\
\text { exceptional } \\
\text { academic and } \\
\text { personal skills } \\
\text { to facilitate the } \\
\text { partnership } \\
\text { process. } \\
\text { 17. Financial } \\
\text { support } \\
\text { 18. The program is } \\
\text { based on a } \\
\text { clear vision of } \\
\text { the needs of the } \\
\text { partnership. } \\
\end{array}$ & $\begin{array}{l}\text { opinions from } \\
\text { different } \\
\text { people. } \\
\text { Cultural } \\
\text { experiences. }\end{array}$ & $\begin{array}{l}\text { the } \\
\text { bureaucratic } \\
\text { systems at each } \\
\text { of the two } \\
\text { universities. }\end{array}$ \\
\hline
\end{tabular}


Strengths are internal factors that can influence an organization or project positively; i.e., its resources, having relevant expertise, positive human relationships, and other internal aspects of value related to the organization and what it does particularly uniquely and well. As mentioned in the table above, multiple factors were identifiable as strengths of the partnership between the two universities. From the perspective of GWU, enthusiasm, enhanced cooperation, and flexibility were key strengths. Indeed, when the researcher worked with the GWU leaders and faculty members and interviewed five faculty members, it was evident that they were very excited about the program. Comments made include:

"Since I first heard about the partnership between our university and the TaibahU team, and recently being involved in this project, I have become really excited about it; especially as it is the first partnership we have had with a Saudi University regarding developing a PhD program in leadership." (Interviewee)

"I am looking forward to dealing with Saudi students and to discussing with them issues related to the course syllabus". (Interviewee)

Based on the researcher's observations and discussions with GWU staff, they appear to be understanding and willing to be flexible. They also sought to understand the Saudi context before engaging in building courses and designing the program's specifications. In addition, holding two workshops at both universities as a main feature of the service contract, played an important role in helping team members at both universities understand each other; encouraging them to discuss diverse issues, including concerning the nature of the students, the culture, courses, facilities, and the systems in place in both universities. Following the workshops, the relationship between the teams became stronger, as well as more flexible and friendly.

As explained above, the first workshop was held at TaibahU, and more than 70 people attended it over a period of five days. On each day, there was a clear target set for the group present. Some Deans from educational colleges at other Saudi universities attended, as did faculty members of the DEA and College of Education. This provided the teams with an opportunity to meet with general education leaders (school principals, supervisors, and representatives of the Education Authority). The workshop also usefully included one day on which postgraduate students were encouraged to give their opinions about the program. During their attendance at this workshop the students showed great enthusiasm and excitement about the program. For example, one student who attended the workshop, and who had nearly finished her PhD in the department and was waiting for her viva, asked the researcher if it would be possible for her to attend the new program established by this partnership.

"Please Dr. Fatemah do your best to allow me and my friends to be students on this new program, we want to be in a new environment, getting new ideas and knowledge from different cultures and systems of education... we want to be illuminated about American schools through new faculty members... As you know, we as girls cannot study abroad for cultural and family reasons". (Workshop attendee)

Both teams' members visited schools and the University College in Yanbu Industrial City to determine whether the current education system is working effectively. Finally, the GWUTaibahU Design Team met for a period of reflection, feedback, to create a final report. Over a period of five working days, a strong partnership developed, and the feedback from all the attendees was informative for all areas of the partnership. TaibahU wrote a report about the workshop for the Ministry of Education, to update them and provide recommendations.

The second workshop held at GWU was also very carefully organized, as mentioned above. The TaibahU team reaped remarkable benefits from their attendance, as did the GWU team. The workshop days gave both teams the opportunity to discuss all the program details face-to-face. Moreover, during the workshop many activities were completed as detailed in the report about it prepared by the teams for the Ministry of Education, including recommendations to also develop additional areas of public and higher education. Multiple additional points and details could be added regarding the two workshops; however, such information will be presented in future work by this author.

The table above reveals that many factors are playing a significant role in strengthening the program, some of which are receiving strong support from TaibahU leaders; i.e. the head of the DEA, The Dean of the College Of Education, the Dean of Postgraduate Studies Affairs, The Dean of Distance Learning and the Vice President himself, who all met with the TaibahU team to discuss items for immediate actioning by TaibahU leaders; e.g., swift approval of the developed Ph.D. program by the TaibahU council, admittance of doctoral students by the following term, and provision of blackboard facilities either via GWU or supported by TaibahU. Other strengths of the program mentioned above, include that it meets the university's stated mission and vision, while also aligning with Vision 2030, which supports partnerships in education and other fields. 
The developed PhD program is understood to be the first and only program at a Saudi university based on academic standards followed by the GSEHD (GWU); and the PMC from GWU offers a credit transfer option to the TaibahU Ph.D. program, offering teaching and cultural experiences, consultations and monitoring. The program allows students to undertake several practice projects, increasing the practical aspects rather than the theoretical ones.

The program also opens the door to research collaborations and joint international conferences (ISEP), teaching and cultural experiences, consultations and monitoring. To achieve all these, the two universities selected team members with excellent academic and personal skills to facilitate the partnership process, and this is considered to be one of the main strengths mentioned by TaibahU leaders and workshop attendees.

As mentioned above, the project was based on a need's analysis, which clarified what the two teams needed, as opposed to a partnership based on course content, research, and student's skills improvement, as faculty members have the opportunity to share experiences.

Weaknesses

Weaknesses are the internal factors within an organization or project that can impede its progress toward set objectives; such as limited expertise, limited access to technology and skills, and lack of resources. The weaknesses identified by this SWOT analysis were small in number, as detailed in the above table. However, some of those listed have significantly affected the project.

It was evident to the researcher, as a member of the partnership at all stages, and from some of the interviews, that the bureaucracy involved has been the principal weakness impeding the project. As evidenced above, approximately seven years elapsed from the moment discussions about the program began, until the signing of the contract, largely due to bureaucracy at the two universities and the need for full centralization at TaibahU. Since signing the contract, the two teams have worked for a further three and a half years, and yet even today, bureaucracy stands in the way of implementation of the program. Despite meeting all the conditions indicated by the universities' administrators, routine procedures continue to delay the delivery of the program.

In addition to bureaucracy, a further weakness has been the high resistance to change from some departmental members, who have expressed strong concerns about the preservation of their roles, identity, language, and culture. Some of the letters and topics raised by team members in the first workshop revealed that faculties were discussing the development of a new section, utilizing only existing faculty members.

The most important weakness, and one that the team is trying to overcome, is that there are too few faculty members to teach the advanced courses across different disciplines. Areas of staffing deficit include in economics and education policy, advanced quantitative and qualitative research, and statistics for scientific research. Additionally, the number of faculty members fluent in English is insufficient, limiting the opportunity to cooperate with members of GWU.

Another weakness is the small number of students fluent in English, and with a low score on the IELTS, STEP and other English tests.

\section{Opportunities}

Opportunities are external factors of interest to the involved parties. They can include, scope for lifestyle changes, resolution of current problems, presence of government support, ease of finding and applying technical knowledge, changes in social patterns, population profiles, lifestyles, and beneficial changes in governance policy. Despite the above mentioned weaknesses, it is apparent that the partnership affords all parties substantial opportunities. The table above lists 12 significant opportunities for the partnership at university level, for faculty members in the College of Education, faculty members of the DEA, and for those students involved in the partnership program.

For the university, such projects contribute to the development of self-financing processes, reducing the heavy reliance on government support, which has begun to fluctuate against the backdrop of new economic conditions and increasing governmental emphasis on self-financing and private sector cooperation with the public sector, to ease the financial burden on the state.

The two workshops revealed considerable interest in debate and enthusiasm among multiple department heads seeking to engage in similar partnership to develop graduate programs in their own departments.

In terms of faculty members, it is apparent that there is now an opportunity in the future to conduct joint research with faculty members from the two universities, opening up horizons to further increase knowledge, experience, and diversity.

With regard to graduate students, who are the target recipients of this partnership, the delivery of a new program and courses will provide students with an opportunity to encounter new knowledge, have diverse cultural experiences, and to be exposed to different teaching methods. They will also have the opportunity to conduct future joint research projects with members of another culture, lending new emphasis to local and international education issues. 
Finally, the program is characterized by its practical intensity, which allows students to enter the field based on a clear academic plan, which is provided by most of the courses, especially the PMC. Students will also have an opportunity to study for three weeks in the USA. Threats

Threats are external factors that can negatively affect performance, or which have the potential to place an organization or an entire project, at risk. For example, competition or negative economic indicators, demographic change, changes in the political and economic environment (Helms \& Nixon, 2010). Typically, whether international or local, partnership projects encounter some threats that could impede the achievement of objectives. In relation to the current partnership, several threats were identified by the researcher and discussed by the team members; these related to the universities and their departments, and in some cases to potential students.

The aforementioned weakness associated with bureaucracy is now considered a threat to the success of the program, especially at TaibahU, as it remains an obstacle to the adoption of the program. The resultant delays could prove disastrous, as the Contract Agreement will expire after a specific time frame. At present, GWU is not expected to allow for extension of the allocated timeframe, and so the team is concerned that the bodies responsible for the accreditation and launch of the program, who are running permanently behind schedule, could cause the cancellation of the partnership in its final stages.

In addition, although the program is complete, the serious issue of intellectual property remains, as was discussed at one of the team meetings. The differences in terms of accreditation and the standards between the two universities was a further weakness that has cost much time; however, the TaibahU team has succeeded in meeting 95\% of the Saudi Accreditation Standards (NCAAA). However, the level of threat will rise if the program is stopped during the final phase and standards change.

The previously mentioned weaknesses arising from a lack of faculty members fluent in English, and the lack of experts in some subjects clearly represents a threat. Moreover, several qualified staff are expected to retire soon, thus increasing the problem; especially since the current economic climate might not facilitate the process of attracting high-quality contractors in future.

With regard to threats relating to the students there are several issues. Most notable is the time difference between the two countries, as there are difficulties determining appropriate communication times for students and faculty members. In addition, commitment to time keeping varies from one culture to another, and the students at Taibah $U$ sometimes have environment-related conditions or cultural ties that limit their capacity to adhere to schedules. In contrast, the faculty members at GWU are meticulous about time keeping because they must complete other tasks. This is especially important, as all the descriptors in the program set strict standards for discipline and attendance.

Another point of potential difficulty is that the program is to be run in its first phase electronically via Blackboard, and there is threat of possible disruption in communication, especially at Taibah $U$, which is still classified as an emerging university. In addition, the new teaching process might be an obstacle for students' who could struggle to interact flexibly, due to differences affecting their learning strategies, language, culture, customs, traditions, and other considerations relating to the students themselves, the university, and the department.

Finally, the big threats that affect the partnership are unexpected and repeated leadership change at TaibahU. The partnership needs to retain enthusiastic and ambitious leaders, but unfortunately the leader of the program was nominated Minister of General Education, creating difficulties for the team. Consequently, some different leaders have been assigned over three consecutive years, causing cost delays and frustration for the entire team, as each new leader has a different strategy and style of leadership and some have been kind of resistant to change. Up to the time of writing, the team had completed everything required to get the program approved and sent to the accreditation agency at TaibahU. However, the new leader has delayed the process, because of his newly introduced policy to bring the regulation process back under his control.

Stage 6: Develop a Strategy

After establishing the specific values related to the partnership offerings based on the four quadrants of the SWOT analysis, this section develops a strategy to capitalize on the identified strengths, to overcome weaknesses, exploit opportunities, and counter threats. Based on all the elements of the SWOT analysis, the researcher attempts below to offer a proposal to guide subsequent steps prior to the launch of the program, capitalizing on strengths and turning weaknesses into opportunities while avoiding threats. 
The SWOT analysis revealed that the strengths and opportunities proposed outweigh the weaknesses and threats. The teams are working hard at both universities to deliver further opportunities to address the threats to the program's implementation.

Turning Weaknesses into Opportunities

Bureaucracy. Bureaucracy was reported as the greatest danger to the program. The two teams have received a lot of pressure to implement the partnership, and time is a concern. However, the delays have provided opportunities to learn about TaibahU's system and to develop negotiation skills, especially among the younger members of the team.

In addition, the TaibahU team was able to limit the influence of bureaucracy to impede the adoption of the program, by conducting a meeting with university directors and leaders to facilitate the implementation of accreditation and to resolve other urgent points that involve universities leaders. This meeting also drew the President's attention to the effort the team has made to accomplish each of the partnership phases and also encouraged him to consider scope for establishing similar partnerships in other departments at the university.

Change resistance. Change resistance emerged clearly as a weakness at the first workshop, but the team succeeded in turning this negative into a positive. The discussion and exchange of different views, resulted in a relatively low level of resistance and cooperation from some former opponents, who then contributed to the work.

With regard to the college of education at TaibahU, this partnership can open the door to other departments, allowing them to update their programs in a variety of ways. In this regard, the Dean of the College asked the researcher and her partner Dr. B to provide a detailed presentation of the partnership to all faculty members within college departments. Therefore, we presented two workshops entitled: 1- Sharing University International Partnership Experiences: Challenges, Successes, and Benefits; and 2- Planning and Designing Academic programs and course syllabi using the TaibahU -GWU approach.

The need to attract qualified staff members to teach the course from other departments. On this particular point, the President promised that the program would represent an opportunity for faculty members from different departments to participate in teaching. This is especially relevant for courses related to research methodology, which are usually taught by faculty members from the Department of Educational Psychology. Thus, faculty members at both universities can share knowledge and course content.

Student's weaknesses in English language: encourage students to learn the English language. At the first workshop, there was a high level of student attendance. The team explained that English language proficiency would determine their acceptance into the program, which led some of them to study English for two years after the contract was signed. Some of them also attained high grades and were ready to submit themselves for admission to the program. Therefore, the department has now set precise conditions to ascertain students' English language abilities, in addition to conducting interviews and written tests.

Avoiding Threats

Some of the threats mentioned in the above table can readily be transformed into opportunities.

Time accuracy and cultural differences. This factor helps both teams to understand the culture of the other; for example, in relation to personal issues and expectations of academic content and time keeping.

Program approval. The program was not quickly adopted by TaibahU. However, this provided time for the team to apply to the accreditation department, and to learn about the accreditation models at GWU in depth, to emphasize the importance of flexibility in the application of standards. A lengthy discussion about this was entered into. The concept of partnership does not necessarily mean a stalemate, with one university model dependent on the other. The focus of the team's work was to present a balance sheet detailing accreditation criteria, for presentation to the Accreditation Committee, as well as to faculty members in the Faculty of Education. All stakeholders engaged in an in-depth discussion about the approval process for academic programs and learned how to deal with issues raised with wisdom and patience. Finally, the program was approved on June 2017.

Technological threat. As the program relies heavily on technology, i.e. using the Blackboard program, some staff members and students were cautious about the method of delivery, in particular whether they would have access to the necessary technology to implement the program. The two teams discussed multiple associated issues, including TaibahU staff training, and during the second workshop held at GWU, the university delivered a training course for the Blackboard program. The members of the TaibahU team learned about the advantages of the program and how access to it could be granted to the students at TaibahU. Following the workshop, the TaibahU team met with TaibahU's postgraduate, admissions, registration, and Distance Learning Deans to discuss the use of Blackboard at the University and to present information learned about the program at GWU. Consequently, a work plan was 
agreed upon to train students and faculty members on the Blackboard program available at TaibahU, to offer the same opportunities as those available at GWU.

Discounting differences in academic standards and requirements. The difference between the two accreditation standards poses a long-term threat. The two teams made considerable effort to reduce the level of difference between expectations at the two universities, as explained previously, and to reach a level of agreement and shared conviction about the program's potential. However, the real threat lies with the accreditation committee at TaibahU, which insisted on following formal standards, which then led to fears among the team arising from the delayed adoption of the program. The TaibahU team has now held an emergency meeting with the Accreditation Committee at the university to explain the scope of the agreed standards, clarifying that the philosophy of the program emphasizes collaboration between two universities that are not necessarily identical, while accounting for and respecting the autonomy of both. To date, despite satisfaction over some points, opposition on others continues to impede the accreditation process.

Student expectations, and faculty-student interactions in different cultural traditions and languages. With regard to this component, both teams discussed this point at the first and second workshops, and faculty members at GWU met teams from TaibahU to discuss the quality of students at the university and to debate how to deal with them in view of their different culture and language. The TaibahU team answered all the questions posed, and explained their plans to overcome these difficulties to avoid any threat to the success of this program. The team explained the allegiance of the students to TaibahU.

Unexpected and repeated leadership change. The next most significant threat to the program after bureaucracy has been the repeated change in team leaders, which creates additional work and extends the length of the process of agreement. To address this the team has tried to bring the new leader up to date quickly, explaining the work conducted to date to reduce his resistance to the project; thus far, their attempts have met with some success.

Stage 7: Produce a Plan

This stage involves building on the strategic plan (Ansoff, 1987), and occurs after the students have been accepted but before implementation of the program. The researcher and her colleagues at this point will focus on discussing execution of the program, and what remains to be prepared based on information identified in previous stages as relevant to the objectives of the partnership. Therefore, action plans are being prepared with a timetable and a note about the starting point, describing the targets to be achieved and who is responsible for what.

Team members at both the universities, TaibahU and GWU, have discussed when to start teaching the courses and who would be teaching at both locations. The TaibahU team members specified a day to host students in the Department of Educational Administration, providing an opportunity to discuss the program and provide the following information:

- Program Description

- Course names and professors

- Guide

- University calendar

- Scientific integrity models

In addition, an appointment was scheduled with the Deanship responsible for distance learning to hold a training course for students regarding the mechanism of the Blackboard program. Arrangements were then made with specific schools to provide access to students for courses requiring fieldwork.

\section{Stage 8: Monitor Progress}

At the time of writing, the program based on this partnership has not yet been implemented. Therefore, this section discusses what the two teams are expecting to do if it is implemented, in terms of monitoring and evaluation. The author, as one of the main representatives of this program, has stressed the need to monitor the partnership during the implementation stage in a systemic way. Monitoring will help the researcher and other team members decide if they are on the right path. If the results are not as expected; i.e., if things go more slowly than anticipated, or if motivation is lost, monitoring will help the teams to establish what action must be taken. Monitoring will be ongoing, and the data collected in this way will help the team plan for the future, to assess the program implementation to ascertain whether the program and the activities are taking place on time, are effective, and if strategies need to be adapted to ensure the best possible results.

The researcher plans to conduct further research to monitor the program in terms of to what extent objectives are achieved; how implementation of the planned activities takes place; how well staff are doing their job in the new program; how much the stakeholders/especially the students beneficiaries are committed; and the impact of changes in situation. During monitoring the researcher also plans to hold discussions in a participatory way with all the 
stakeholders/beneficiaries involved. Identification of emerging concerns will help with future planning. Best practices can be used again, and practices which do not work can be eliminated. This project needs this kind of monitoring as it is a new project, and many of the obstacles that will arise would also need to be avoided in other similar future projects at TaibahU. After monitoring the program the researcher also planned to share the lessons learned from this project with policy makers, highlighting issues with bureaucracy that have been instrumental in hindering the progress of the program.

Limitations and Strengths of the Study

As apparent from the title of the research, the scope and limitations of the current study are twofold: first, the research deals with the example of a single partnership at TaibahU, so there is no possibility to generalize the data. Second, the current study deals only with the preimplementation phase of the partnership. However, these limitations are not of significant concern in terms of the research aims. Generalization was not an objective of the current study, as the researcher wished to conduct a deep analysis of this specific partnership. Additionally, the researcher is intending in the future to compare the partnership described with similar partnerships at other Colleges of Education throughout Saudi Arabia, and so the SWOT analysis presented here is intended simply to provide the Ministry of Education with a clear vision of the benefits of such future partnerships. In relation to the second limitation, that of dealing only with the current period of the partnership, this is inevitable based on the progress to date, and the researcher plans to prepare additional evaluative and monitoring studies throughout the implementation phases of the program, as a follow up to this report. The current research offers an essential analysis of the first period of this partnership, which is at present considered unique in terms of the level of cooperation it demonstrates between team members at both universities, who have been putting equal efforts into amicably bringing the partnership project to fruition. Finally, limitations effect any form of human activity, not only research; claims to perfection can rarely be made, and researchers have to do their best with the resources and time available.

Despite the limitations mentioned, this research has notable strengths. First, the researcher herself is a representative member of the partnership team, and was, is, and will be involved in all phases of the service contract. Thus, she is in a singular position to observe and analyze the strengths, weaknesses, opportunities, and threats to the project. Second, the researcher conducted some unstructured interviews to collect data for the SWOT analysis. Third, one of the main phases of the partnership was the holding of two workshops at both universities, which afforded many advantages to both the researcher and the other team members at both universities, helping them to understand each other's educational contexts and enabling them to devise a successful program.

\section{Conclusion}

In conclusion, this research has demonstrated that the international partnership between TaibahU and GWU supports the objectives stated in Vision 2030 for the Kingdom of Saudi Arabia. The aim of this study was to explain the progress of an international partnership being trialed between a Saudi and American university, using a SWOT analysis to highlight the strengths, weaknesses, opportunities and challenges arising from this relationship. Conducting this analysis has allowed the researcher, as one of the representatives of the partnership, to examine the project's progress to date in depth while focusing on the continuing value of the partnership.

The project discussed is unique in that it is truly innovative, and founded on genuine intellectual participation between two working groups, who are aiming to mutually devise a curriculum that suits the aspirations expressed in Vision 2030. However, this study has revealed that the program has some strengths, weaknesses, and threats, which when combined represent a number of important opportunities to ensure the successful conclusion of the partnership. The two teams have made considerable efforts to establish professional cooperation, and successful realization of the project objectives is in sight; however, minor obstacles relating to bureaucracy at the Saudi University remain.

This research introduced and reviewed the phases of the partnership to date, covering a period of 8 years since the contract was signed between the project teams. The researcher plans future research to monitor and evaluate the implementation phase once it commences, to assess the partnership and identify issues and make recommendations on points to be improved on in the future. Certainly, developing a new PhD program in leadership through such a partnership is a new phenomenon in the context of Saudi universities. The Ministry of Education has been responsible for ensuring the partnership's existence, and is regularly following-up the program. The TaibahU team has provided detailed reports to the Ministry of Education and has also received encouragement and support.

The partnership described preludes new opportunities for other academic departments in the university, and at other Saudi universities, wishing to benefit from international partnership arrangements. As explained previously, many faculties at the university have already welcomed a 
presentation from the team about the discussed partnership and the stages involved, as have staff at other universities in the Kingdom. The team has already delivered five presentations to share their experiences with others, and to exchange opinions on the inputs and outputs of the program, to determine how it can be most successfully realized.

In conclusion, we can confirm that this research answered the questions posed by the researcher at the start, concerning events to date and the next steps required to push the program forward. At the time of writing, TaibahU has several service contracts with nine other universities from around the world: the University of Manchester, GWU, Pennsylvania State University, The Higher Education Academy, The University of Pittsburgh, The University of British Columbia, Universiti Teknologi Malaysia (UTM), the International Islamic University Malaysia (IIUM), and Tshwane University of Technology (Taibah University, 2017a). All these partnerships are serving to develop the university in multiple ways. Projects include introducing a new medicine curricula and methods of teaching and learning, offering professional development for faculty members, harnessing technology to improve the acoustics in the second Holy Mosque, the development of quality assessment systems, and developing essential scientific research into flood management and the valley layout in Almadinah Amunnawarah City.

Consequently, the researcher is intending in the future to compare the current partnership with other partnerships at TaibahU. In addition, the researcher also plans future research monitoring and evaluating the implementation stages of this partnership. 


\section{References}

Ansoff, I. (1987). Corporate strategy. London: Penguin.

Cohen, L., Manion, L., \& Morrison, K. (2007). Research methods in education. London: Routledge, Falmer.

Helms, M. M., \& Nixon, J. (2010). Exploring SWOT analysis - Where are we now?: A review. Journal of Strategy and Management, 3, 215-251. doi:10.1108/17554251011064837.

Jie, Y. (2010). International partnerships: A game theory perspective. New Directions for Higher Education, 2010, 43-54. doi:10.1002/he.389.

Kadushin, C., Hecht, S., Sasson, T., \& Saxe, L. (2008). Triangulation and mixed methods designs: Practicing what we preach in the evaluation of an Israel experience educational program. Field Methods, 20, 46-65. doi:10.1177/1525822X07307426.

Kotler, P., Armstrong, G., Harris, L. C., \& Piercy, N. F. (2013). Principles of marketing. Harlow: Pearson.

Ministry of Education. (2010). The general department of planning and statistics. Riyadh: Ministry of Educational Press.

Rashad, M. (2016). Saudis await Prince's vision of future with hope and concern. Reuters. Retrieved from http://www.reuters.com/article/us-saudi-plan-idUSKCNOXL0B2

Sallis, E. (1990). Corporate planning in an FE college. Educational Management and Administration, 18, (30-34). doi:10.1177/174114329001800206.

Samoff, J., \& Carrol, B. (2004). The promise of partnership and continuities of dependence: External support to higher education in Africa. African Studies Review, 47, 67-199. doi:10.1017/S0002020600027001.

Smith, J., Harre, R., \& Vanlangenhove, L. (1999). Rethinking methods in psychology. London: Sage Publications.

Taibah University. (2017a). About Taibah university. Retrieved from https://www.taibahu.edu.sa/Pages/en/CustomPage.aspx?ID=47

Taibah University. (2017b). A brief description of Taibah University. Retrieved from https://www.taibahu.edu.sa/Pages/AR/Sector/SectorPage.aspx?ID=94\&PageId=201.

Taibah University. (2017c). The department of educational administration. Retrieved from https://www.taibahu.edu.sa/Pages/AR/Sector/SectorPage.aspx?ID=24\&PageId=1874. 
Pجلة كلية التربية بالإسماعيلية - العدد الثامن والثثلاثون - مايو Pá

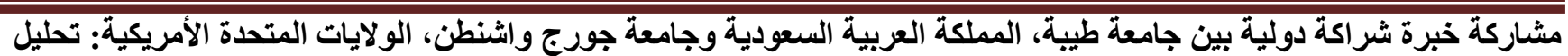
سوات الرباعي ووضع خطة فيرة استراتيجية.

\title{
فاطمة عبدالله الهازمي، جامعة طيبة
}

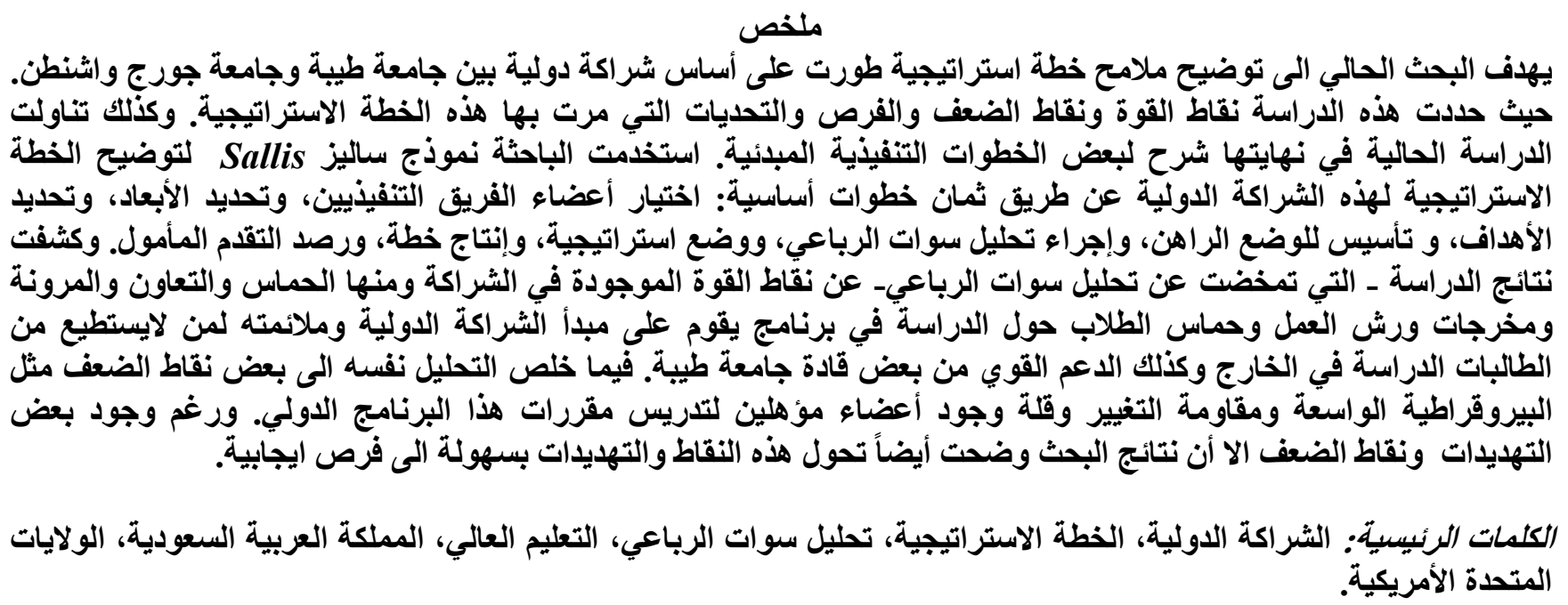

Shared International Partnership Experience between Taibah University, KSA and George Washington University, USA: A SWOT Analysis and Strategic Plan

\begin{abstract}
The present research clarifies the strategic plan developed informing the basis of the partnership between TaibahU and GWU, and identifies the strengths, weaknesses, opportunities, and threats that emerged in the planning stages, concluding with the pre-implementation stage. The researcher uses Sallis' model to clarify the strategic plan for the partnership, employing eight steps: Select team members, Specify the horizon, Set objectives, Establish present position, Undertake the SWOT analysis, Develop a strategy, Produce a plan and Monitor progress. The findings from the SWOT revealed strengths present in the partnership, such as GWU's enthusiasm, cooperativeness, flexibility, benefits of workshops and students' enthusiasm about studying on a program based on a partnership project, suitability for female students who cannot access study abroad, and strong support from TaibahU leaders. Weakness to address included the extensive bureaucracy, resistance to change, and the lack of qualified members of staff available to teach courses. However, the current research also showed that some weaknesses threats readily be transformed into opportunities.
\end{abstract}

Keywords: International partnership, strategic plan, SWOT analysis, higher education, Saudi Arabia, the USA. 